\title{
M-BACOD Regimen
}

National Cancer Institute

\section{Source}

National Cancer Institute. m-BACOD Regimen. NCI Thesaurus. Code C63458.

A regimen consisting of methotrexate, bleomycin, doxorubicin, cyclophosphamide, vincristine and dexamethasone used to treat aggressive forms of non-Hodgkin lymphoma. 